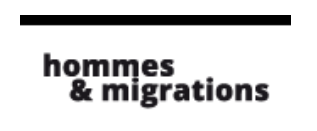

\section{Hommes \& migrations}

Revue française de référence sur les dynamiques

migratoires

$1311 \mid 2015$

Femmes et migrations

\title{
Juliette Minces, De Gurs à Kaboul. Entretien avec Luc Desmarquest. Postface de Michel Wieviorka
}

La Tour d'Aigues, édition de l'Aube 2015, 320 pages, $20 €$

\section{Mustapha Harzoune}

\section{(2) OpenEdition}

Journals

Édition électronique

URL : http://journals.openedition.org/hommesmigrations/3405

DOI : $10.4000 /$ hommesmigrations.3405

ISSN : 2262-3353

Éditeur

Musée national de l'histoire de l'immigration

Édition imprimée

Date de publication : 1 juillet 2015

Pagination : 197-198

ISBN : 978-2-919040-32-2

ISSN : 1142-852X

Référence électronique

Mustapha Harzoune, « Juliette Minces, De Gurs à Kaboul. Entretien avec Luc Desmarquest. Postface de Michel Wieviorka », Hommes \& migrations [En ligne], 1311 | 2015, mis en ligne le 09 février 2016,

consulté le 24 septembre 2020. URL : http://journals.openedition.org/hommesmigrations/3405 ; DOI : https://doi.org/10.4000/hommesmigrations.3405

Ce document a été généré automatiquement le 24 septembre 2020.

Tous droits réservés 


\section{Juliette Minces, De Gurs à Kaboul. Entretien avec Luc Desmarquest. Postface de Michel Wieviorka}

La Tour d'Aigues, édition de l'Aube 2015, 320 pages, $20 €$

\section{Mustapha Harzoune}

\section{RÉFÉRENCE}

La Tour d'Aigues, édition de l'Aube 2015, 320 pages, $20 €$.

1 Juliette Minces fit partie durant de nombreuses années du comité de rédaction de la revue. Une fois n'est pas coutume, nous évoquerons le livre si ce n'est d'une amie à tout le moins d'une relation à la présence toujours amicale et souriante. Cette proximité ne sera pas complicité, même si ces entretiens sont rares. Rares parce que Juliette Minces parle avec une franchise qui ne court plus les rues. Ses propos sont sans arrièrepensées. Pas de double fond ici. Elle ne soupèse pas ses mots au trébuchet d'une carrière ou d'une posture, d'un rapport de séduction ou d'intérêt. C'est en toute sincérité qu'elle évoque son enfance, sa famille, Ménilmontant, son parcours de fille unique d'un couple d'émigrés juifs polonais, l'internement, avec Esther, sa mère, dans le camp de Gurs. Ensuite viendra le temps des engagements: de l'indépendance algérienne à la défense des femmes afghanes en passant par la cause kurde. Juliette Minces ne cache pas ses fragilités, Gurs et ses séquelles, son sentiment d'illégitimité, sa peur de d'abandon, ses fantômes, ses moments de dépression aussi, jusqu'à ses « échecs»: "J'ai construit ma maison sur des dunes mouvantes." Aujourd'hui il y a les épreuves de l'âge, la « solitude » et le «trop tard » confié « le cœur serré ».

2 Sociologue, franc-tireur de la pensée française, Juliette Minces a écrit et enseigné sur le monde ouvrier, l'immigration, l'islam, le féminisme. Par convictions, héritées en partie de ses parents communistes, et par choix, elle a toujours été aux côtés de l'humanité souffrante. En toute liberté: loin des appareils, des carcans idéologiques et des 
gratifications institutionnelles. Libre donc! En refusant de faire joujou avec les sirènes du paternalisme et de la victimisation, cette liberté elle ne la refusa pas non plus aux immigré(e)s. C'est aussi pourquoi, à l'Idée de l'immigré, elle a toujours préféré l'immigré. En chair et en os. À la « discourite » (dixit Driss Chraïbi), elle préfère le « goût du concret ", "rendre la réalité palpable», "donner la parole à mes interlocuteurs». Et comme "le monde est une branloire pérenne», sa pensée est restée, là aussi, libre. Toujours vigilante. Ainsi, en ces temps de mondialisation, elle invite encore «à réfléchir différemment, y compris aux rapports sociaux, au lieu de rester cloué par des habitudes de pensée qui remontent au XIXe siècle ».

3 C'est à Gurs, parmi les détenus de nationalités diverses, qu'elle fait l'apprentissage de l'internationalisme ou du cosmopolitisme. Cette expérience donnera, dans le feu des engagements futurs, un viatique et une éthique : "J'ai découvert combien les besoins des êtres humains étaient universels, malgré des cultures différentes et des religions étouffantes. C'est pourquoi je ne suis pas tombée dans le culturalisme quand j'ai commencé à travailler sur l'immigration. " D'ailleurs, «je crois qu'on crée des problèmes psychologiques quand on traite les gens différemment, en insistant sur les différences plutôt que sur les similitudes ». Cela commence sur les bancs et les cantines de l'école publique.

4 C'est aussi à Gurs que naît la colère inentamée : «Trop de choses me rappellent le passé, et pas le meilleur: qu'il y ait aujourd'hui encore des camps de rétention où on regroupe des gens avec des enfants, des expulsions sans véritables raisons, un racisme accru, des amalgames dangereux concernant immigrés, réfugiés, demandeurs d'asile... Le taux de chômage et la richesse insolente de certains me révulsent, mais je n'agis plus. Pourtant, ayant séjourné à Gurs, je devrais être plus active. Mais je n'en ai plus la force. "

5 Ici, loin de s'opposer, éthique de conviction et éthique de responsabilité se complètent et se renforcent. Voilà aussi pourquoi ces entretiens sont rares.

\section{AUTEURS}

\section{MUSTAPHA HARZOUNE}

Journaliste 